\title{
Regeneração endodôntica em dente permanente jovem portador de necrose pulpar e rizogênese incompleta: relato de caso clínico
}

\author{
Endodontic regeneration in permanent tooth young carrier necrosis of the pulp
} and the formation of roots incomplete: case report

Regeneración endodóntica en diente permanente joven con necrosis pulpar y rizogénesis incompleta: reporte de caso

Karina Gonzalez Câmara FERNANDES ${ }^{1}$

Nathalia Mariko Assakawa SEKI ${ }^{2}$

Lucieni Cristina Trovati MORETI ${ }^{\mathbf{1}}$

Luciana Estevam SIMONATO ${ }^{3}$

Marlene Cabral Coimbra CRUZ $^{4}$

Nilton César Pezati BOER $\mathbf{1}^{\mathbf{1}}$

'Professor(a) das Disciplinas de Endodontia e Clínicas Integradas do Curso de Odontologia da Universidade Brasil, 15600-000 Fernandópolis - SP, Brasil

${ }^{2}$ Graduanda do Curso de Odontologia da Universidade Brasil,15600-000 Fernandópolis - SP, Brasil

${ }^{3}$ Professora das Disciplinas de Estomatologia e Semiologia do Curso de Odontologia da Universidade Brasil, 15600-000 Fernandópolis - SP, Brasil

${ }^{4}$ Professora das Disciplinas de Saúde Coletiva e Imaginologia do Curso de Odontologia da Universidade Brasil, 15600-000 Fernandópolis - SP, Brasil

\section{Resumo}

A terapia endodôntica de dentes com morte pulpar e rizogênese incompleta é complexa representando um desafio aos endodontistas, exigindo muita habilidade profissional. E para esses casos, uma alternativa promissora vem sendo muito utilizada, conhecida como regeneração ou revascularização pulpar. Esta técnica é menos invasiva quando comparada a técnica tradicional (apicificação), sendo que na revascularização pulpar por meio de um estímulo ocorre a invaginação de um novo tecido para o interior do canal, permitindo assim a regeneração dos tecidos danificados, devolvendo suas condições fisiológicas de vitalidade. O objetivo deste trabalho será descrever um tratamento de revascularização em um dente permanente jovem com ápice aberto que sofreu necrose pulpar após a ocorrência de um trauma. Conclusão: De acordo com os resultados obtidos; concluímos que houve regressão completa de sintomatologias, involução da fístula sem recidiva, resposta positiva ao teste de vitalidade pulpar, além do contínuo desenvolvimento radicular e regeneração do tecido danificado, comprovando assim a efetividade da técnica.

Descritores: Raiz Dentária; Necrose da Polpa Dentária; Hidróxido de Cálcio; Regeneração.

\begin{abstract}
Endodontic therapy of teeth with pulp death and incomplete rhizogenesis is complex, posing a challenge to endodontists, requiring a great deal of professional skill. And for these cases, a promising alternative has been widely used, known as regeneration or pulpal revascularization. This technique is less invasive when compared to the traditional technique (apicification), and in pulpal revascularization by means of a stimulus, the invagination of a new tissue into the canal, thus allowing the regeneration of the damaged tissues, returning their physiological conditions of vitality. The objective of this work will be to describe a treatment of revascularization in a permanent young tooth with open apex that suffered pulp necrosis after the occurrence of a trauma. Conclusion: According to the results obtained; we conclude that there was complete regression of symptoms, involution of the fistula without recurrence, positive response to the pulp vitality test, as well as the continuous root development and regeneration of the damaged tissue, thus proving the effectiveness of the technique.

Descriptors: Tooth Root; Dental Pulp Necrosis; Calcium Hydroxide; Regeneration.
\end{abstract}

\section{Resumen}

El tratamiento endodóntico de dientes con la muerte de la pulpa y la formación de raíces incompleta es compleja, lo que representa un reto para los endodoncistas, lo que requiere de mucha habilidad profesional. Y en estos casos, una alternativa prometedora ha sido ampliamente utilizado, conocido como la regeneración de la pulpa o la revascularización. Esta técnica es menos invasiva en comparación con la técnica tradicional (apexificación) y la revascularización de pulpa por un estímulo, invaginación de tejido nuevo en el canal, lo que permite la regeneración de tejido dañado, la devolución de las condiciones fisiológicas de la vitalidad. El objetivo de este estudio es describir un tratamiento de revascularización en los dientes joven permanente con ápice abierto que sufrió necrosis de la pulpa después de la ocurrencia de un trauma. Conclusión: De acuerdo con los resultados obtenidos; Se concluyó que no había una regresión completa de los síntomas, sin respuesta positiva recurrencia fístula involución a la vitalidad de la prueba de la pulpa, así como el desarrollo de la raíz continua y la regeneración de tejido dañado, lo que demuestra la eficacia de la técnica.

Descriptores: Raíz del Diente; Necrosis de la Pulpa Dental Hidróxido de Calcio; Regeneración.

\section{INTRODUÇÃO}

A terapia endodôntica de dentes com necrose pulpar e rizogênese incompleta é complexa, sendo encarado como um grande desafio aos endodontistas, pois para atingir ao sucesso do tratamento, requer um treinamento clínico adequado do operador ${ }^{1}$.

Traumatismo nos dentes e estruturas de suporte é um problema frequente, sendo assim, o tratamento endodôntico é necessário para 41,3\% dos dentes que sofrem essas injúrias traumáticas. Com a ocorrência do trauma pode ocorrer à interrupção do suprimento sanguíneo da polpa levando à necrose pulpar. A polpa necrótica é um ambiente apropriado para que os microrganismos liberem suas toxinas na região perirradicular, causando uma reação inflamatória e lesões periapicais. Dois dos critérios mais importantes para o tratamento endodôntico ser bem-sucedido são a eliminação de microrganismos e a vedação apical ${ }^{1,2}$. 
Dentes necrosados com ápice aberto tradicionalmente recebem um tratamento denominado de apicificação. Cujo procedimento consiste na aplicação de pasta de hidróxido de cálcio, com o objetivo de induzir o fechamento do ápice. Porém, sua desvantagem está na necessidade de um tempo relativamente longo (9-24 meses) e apesar de proporcionar um fechamento apical, e por vezes o desenvolvimento radicular apical, não permite o aumento de espessura das paredes do canal radicular, tornando-o friável ${ }^{2}$.

O conceito de revascularização do tecido pulpar; pode ser uma alternativa promissora nos casos de dentes imaturos com necrose pulpar. A endodontia regenerativa propõe o controle da infecção do sistema de canais radiculares, com a mínima intervenção dos instrumentos e irrigação excessiva. Vários protocolos têm sido propostos com variáveis pequenas, sem um consenso entre os autores ${ }^{2}$.

A revascularização pulpar é uma alternativa de tratamento que estimula a formação de um novo tecido no interior do canal ${ }^{3}$. A vantagem desta técnica comparada à tradicional, é que consiste ser menos dispendiosa, menos invasiva, e acima de tudo, consiste em restituir tecidos perdidos, é autólogo (o que diminui a quase zero a rejeição), não debilita estruturas adjacentes, e ainda devolve a condição fisiológica de vitalidade ao tecido ${ }^{4,5}$.

O objetivo deste trabalho será descrever o tratamento de revascularização em um dente permanente jovem com ápice aberto que sofreu necrose pulpar após a ocorrência de um trauma.

\section{CASO CLÍNICO}

Paciente B.F.T., sete anos de idade, do gênero feminino, leucoderma, compareceu a clínica Odontológica, no período de fevereiro de 2015 , após a ocorrência de um trauma em virtude de uma queda, atingindo os incisivos centrais superiores. Foi realizada anamnese, exame físico intra e extraoral, além de exames complementares como a radiografia (Figura 1). Neste primeiro atendimento os elementos 11 e 21 apresentavam vitalidade, na percussão horizontal não apresentava dor em nenhum dos elementos e na percussão vertical leve desconforto no elemento 11, sendo assim foi proposta a família a proservação do caso por se tratar de dente jovem com rizogênese incompleta.

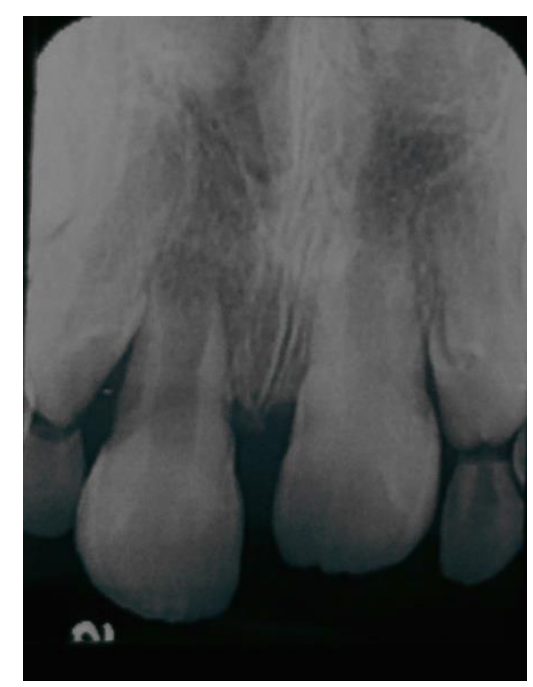

Figura 1: radiografia inicial dos incisivos centrais Aspecto da rizogênese incompleta.

A paciente retornou após 3 meses para realização do teste térmico e de percussão nos elementos afetados pelo trauma, exame radiográfico (Figura 2), sendo que até aquele momento os sinais eram de normalidade. Ao retornar para acompanhamento no mês de julho, 5 meses após o ocorrido, foi identificado uma fístula na região do elemento 11 , com teste de sensibilidade negativo neste elemento e positivo no 21 , percussão horizontal e vertical negativas em ambos, teste de sondagem negativo em ambos e novo exame radiográfico foi realizado (Figura 3). Em virtude do amplo diâmetro do forame apical, necrose recente com chance de recuperação e paciente jovem com maior número de células indiferenciadas, o tratamento proposto foi revascularização pulpar.

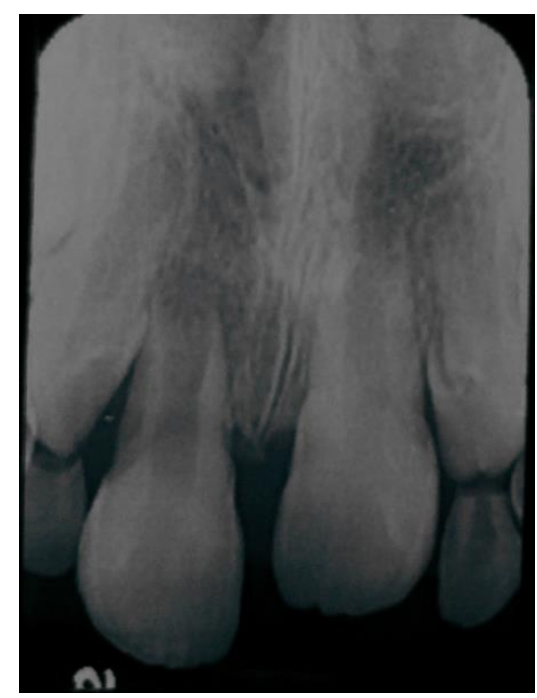

Figura 2: radiografia de acompanhamento após 3 meses do trauma

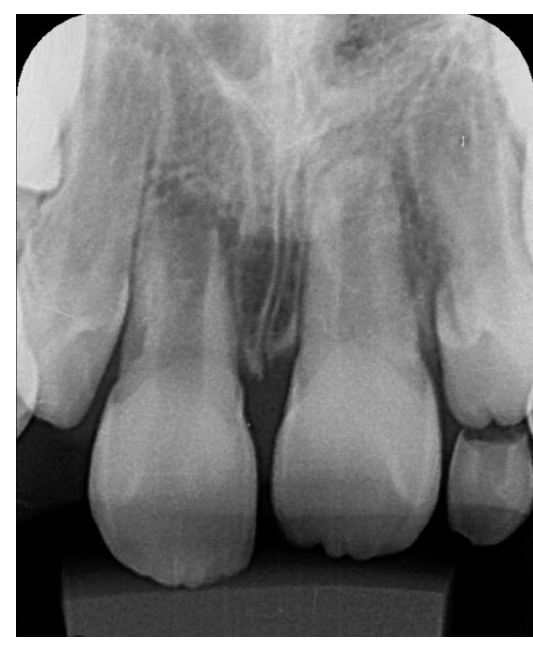

Figura 3: radiografia de proservação, 5 meses após o trauma com necrose pulpar no dente 11 .

$\mathrm{Na}$ primeira sessão do tratamento, foi realizada a anestesia infiltrativa e em seguida a cirurgia de acesso com a broca 1014 HL e isolamento absoluto. Sob o isolamento absoluto foi feito a descontaminação do conduto, através de uma irrigação lenta e copiosa com hipoclorito de sódio $2,5 \%$. Uma suave instrumentação foi realizada nas paredes dentinárias com lima tipo $\mathrm{K} 40$ e abundante irrigação e aspiração da solução irrigadora. Após a instrumentação e aspiração de todo hipoclorito, o canal foi inundado com quelante EDTA trissódico a $17 \%$ por três minutos e irrigação final (seguida de aspiração) com soro fisiológico e secagem com pontas de papel absorventes esterilizadas. Em seguida foi manipulado sobre uma placa de vidro o medicamento intracanal com hidróxido de cálcio P.A e propilenoglicol, e posteriormente introduzido até preencher totalmente o canal radicular. $\mathrm{O}$ selamento provisório foi realizado com ionômero de vidro.

Após 21 dias, na segunda sessão do tratamento regenerativo, foi realizada a anestesia infiltrativa, com remoção do material selador e isolamento absoluto. Realizou-se uma abundante irrigação com solução fisiológica para remover toda medicação intracanal. A indução do coágulo sanguíneo foi provocada com uma lima tipo K 70 na região periapical, ultrapassando o forame apical não mais que $3 \mathrm{~mm}$, o que gerou um sangramento no interior do canal e em consequência a formação do coágulo sanguíneo no mesmo. Este coágulo foi tamponado por 10 minutos, onde foi acomodada uma esponja hemostática de 
colágeno (hemospon) sobre o coágulo para mantê-lo em posição, e colocado uma barreira cervical com cimento reparador Agregado de Trióxido Mineral (MTA), e na sequência realizou-se o selamento provisório com ionômero de vidro finalizando a segunda sessão (Figura 4). Passados alguns dias, a paciente retornou para terceira sessão e o selamento provisório foi substituído por uma restauração definitiva com resina composta.

Em fevereiro de 2016, 7 meses após o procedimento de regeneração pulpar, a paciente retornou com regressão completa de sintomatologia e com resposta positiva ao teste de vitalidade pulpar (Figura 5). Um novo exame radiográfico foi realizado, após 1 ano e 1 mês do término do tratamento para acompanhamento do mesmo, demonstrando a continuidade do desenvolvimento radicular, a regeneração do tecido danificado (Figura 6).

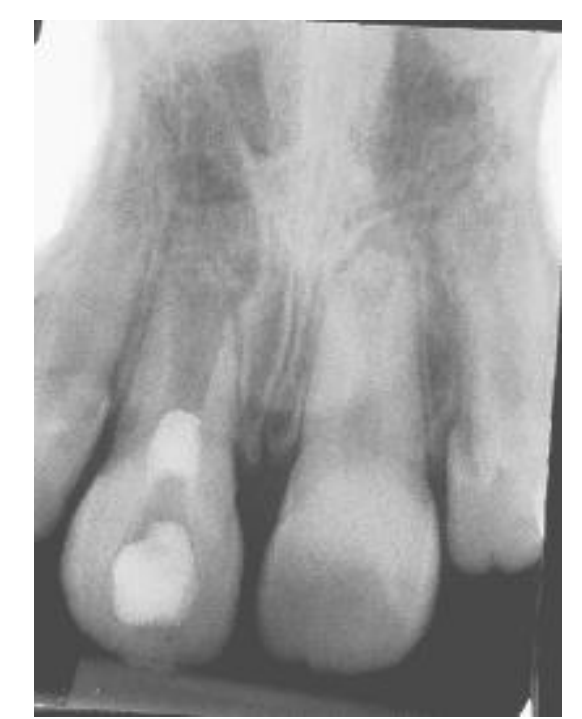

Figura 4: exame radiográfico após a indução do coágulo e colocação do MTA

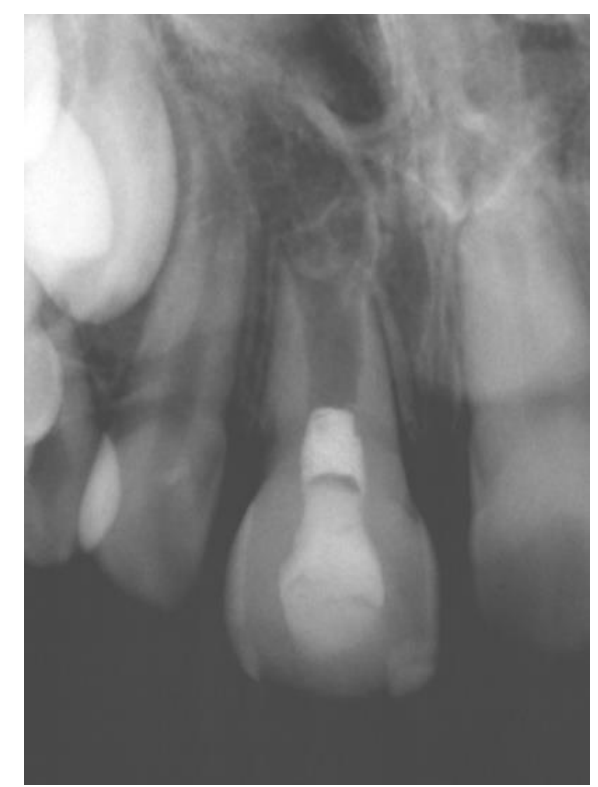

Figura 5: radiografia de proservação após 7 meses do tratamento.

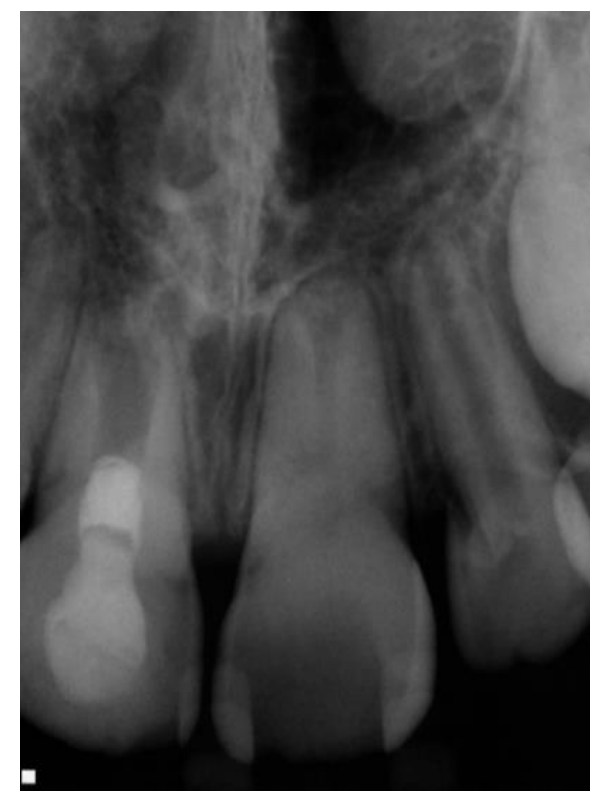

Figura 6: Proservação do elemento 11- controle radiográfico após 1 ano e 1 mês.

\section{DISCUSSÃO}

Jung et al. $^{6}$ afirmaram em seu estudo que a endodontia regenerativa pode ser definida como um tratamento que visa o direcionamento biologicamente controlado da regeneração ou reparo do tecido danificado. Esses mecanismos ocorrem nas estruturas do complexo dentino-pulpar, originando tecidos viáveis, de preferência da mesma origem, que restabeleçam as funções fisiológicas desse complexo.

Hargreaves et al. $^{7}$ explicam que para a compreensão da regeneração pulpar alguns fatores devem ser levados em consideração, como a presença de células-troncos, fatores de crescimento e uma matriz de crescimento. Além disso, é necessário um microambiente favorável a proliferação e diferenciação celular. Mas, para que isso ocorra, é necessário o controle da infecção do canal radicular.

A sanificação é alcançada por meio de um preparo mínimo, irrigação abundante e medicação intracanal satisfatória. Apesar do alto índice de sucesso apresentados na literatura, ainda não há um consenso em relação ao protocolo na prática clinica deste tratamento, principalmente em relação à solução irrigadora e a medicação intracanal mais recomendada ${ }^{8}$.

Lovelace et al. ${ }^{3}$ relataram em seu estudo que a etapa fundamental para que a regeneração pulpar ocorra é a descontaminação dos sistemas de canais radiculares. Portanto, em dentes imaturos a remoção de microrganismos por meios mecânicos é limitada devido á fina espessura das paredes dentinárias, assim a limpeza do canal geralmente é obtida por meio de irrigação e medicação intracanal. No presente caso clínico a instrumentação foi realizada suavemente sobre as paredes do canal com lima tipo K 40 e posterior irrigação abundante.

Dentre as substâncias químicas mais utilizadas para este procedimentos temos o hipoclorito de sódio $(\mathrm{NaOCl})$ e gluconato de clorexidina (CLX), sendo a primeira mais utilizada e com maior aceitação a nível mundial. As duas principais propriedades do hipoclorito de sódio são: ação antimicrobiana potente e capacidade de dissolução de tecido orgânico ${ }^{9}$. Tanto o hipoclorito de sódio quanto a clorexidina apresentam bom potencial antimicrobiano, porém permanece a implicação da utilização da clorexidina devido a sua ineficiência na dissolução de tecidos orgânicos ${ }^{10}$.

$\mathrm{Na}$ terapia de regeneração pulpar as concentrações do hipoclorito de sódio variam entre $2,5 \%$ a $6 \%$, tendo apresentado resultados satisfatórios ${ }^{11}$. Sendo que no caso apresentado foi utilizado hipoclorito de sódio a 2,5\% e neutralização com solução fisiológica. Segundo Shin et al. ${ }^{12}$ e Reynolds et al. ${ }^{13}$ a irrigação final com solução fisiológica abundante, possui um efeito neutralizante, sendo essa de suma importância para diminuir a citotoxidade para as células-troncos e impedir a interação das moléculas de hipoclorito de sódio as da clorexidina quando são associadas no mesmo tratamento pulpar.

De acordo com Galler et al. ${ }^{14}$ usar apenas as soluções irrigadoras não são suficiente, sendo necessário e indispensável também o uso das soluções quelantes como o EDTA. Graham et al. ${ }^{15}$ acreditam que as soluções quelantes, além de remover a smear layer, são capazes de fazer com que vários fatores de crescimento presentes na matriz dentinária humana sejam liberados. Porém, não se sabe ainda se quando o canal radicular é irrigado com EDTA este pode promover a proliferação das células indiferenciadas responsável pela revascularização ${ }^{7}$. Trevino et al. $^{9}$ demonstraram em seu estudo que o EDTA auxilia na 
sobrevivência das células troncos apicais. A irrigação com a solução quelante foi usada no presente estudo, sendo realizada na primeira sessão após a desinfecção do conduto e anteriormente a introdução do medicamento intracanal.

Turkistani e Hanna et al. ${ }^{16}$ reforçaram em seu estudo que o processo de revascularização pulpar é mais favorável em ambiente livre de bactérias, fazendo-se necessário a limpeza e descontaminação do canal radicular, uma vez que a desinfecção do canal só é concluída com a utilização do curativo de demora.

O medicamento intracanal utilizado neste estudo foi o hidróxido de cálcio, sendo que o mesmo tem sido utilizado em tratamentos de regeneração pulpar e apresentando índices de sucesso semelhantes à pasta tri-antibiótica 17,10. Segundo Bose et al. ${ }^{18}$ tanto o hidróxido de cálcio quanto a pasta tri-antibiótica auxiliam o desenvolvimento do complexo dentino-pulpar. Pesquisas demonstraram que o hidróxido de cálcio é capaz de solubilizar moléculas bioativas, inclusive fatores de crescimento o que por sua vez pode estimular células pulpares indiferenciadas a se diferenciarem em células semelhantes aos odontoblastos produzindo assim tecido similar a dentina ${ }^{15}$.

Dhillon et al. ${ }^{19}$ relataram que transcorrido os 30 dias após a primeira sessão e o paciente apresentar-se assintomático, será estimulado um sangramento apical fazendo com que o sangue preencha todo o canal radicular até a junção cemento-esmalte e com a formação do coágulo uma matriz de colágeno é colocada sobre o mesmo servindo de base para o MTA. Os procedimentos realizados no caso clínico deste trabalho seguiram estes passos, com uma pequena alteração, pois aos 21 dias após a primeira sessão foi realizada a estimulação e o tamponamento cervical com MTA.

A formação de um coágulo associado ao tecido pulpar necrosado funciona como um arcabouço ("scaffold') para o crescimento do novo tecido, onde células-tronco indiferenciadas possivelmente provindas da papila apical, e a presença de fatores de crescimento, provavelmente liberados de plaquetas e dentina irão direcionar a diferenciação celular $^{20,3}$. Souza et al. ${ }^{21}$ salientaram que as células mesenquimais indiferenciadas do tecido invaginado, em contato com a parede dentinária, sintetizam e secretam um tecido tipo cementoide que se forma em camadas e, sucessivamente, promove um fechamento do espaço e reforça a estrutura do canal radicular.

Ding et al. ${ }^{22}$ afirmaram em seu estudo que após a formação do coágulo, a confecção de um plug com MTA tem sido utilizada para vedar a entrada de bactérias, ocasionando um selamento do canal radicular para posteriormente receber a restauração com compostos resinosos. O agregado de trióxido mineral (MTA) apresenta propriedades antimicrobianas, além de ser um material capaz de ganhar presa mesmo na presença de umidade $23,24,25$. Sendo indicado para função de blindar o canal radicular, este material foi empregado no estudo apresentado como barreira cervical sobre o coágulo sanguíneo, para em seguida inserir o material restaurador provisório.

O acompanhamento dos casos clínicos realizados por meio de revascularização pulpar é fundamental para verificar o sucesso clínico. Geralmente o tempo necessário para identificar algum progresso do tratamento realizado é de no mínimo 6 meses ${ }^{18,26}$. Chueh et al. ${ }^{27}$ observaram que a formação completa da raiz de dentes imaturos portadores de necrose pulpar e lesão periapical se desenvolveu completamente em um período que variou de 10 a 13 meses do inicio do tratamento.
Transcorridos 13 meses de acompanhamento, foi possível identificar no presente caso clínico regressão completa de sintomatologia, resposta positiva ao teste de vitalidade pulpar, além do contínuo desenvolvimento radicular e reparo do tecido danificado.

De acordo com a Associação Americana de Endodontia (AAE) o sucesso clínico da regeneração pulpar se dá quando alcança dois objetivos sendo: eliminação dos sintomas e reparo das estruturas periapicais, espessamento das paredes dentinárias e formação radicular 8 .

\section{CONCLUSÃO}

De acordo com os resultados obtidos; concluímos que houve regressão completa de sintomatologias, involução da fístula sem recidiva, resposta positiva ao teste de vitalidade pulpar, além do contínuo desenvolvimento radicular e regeneração do tecido danificado, comprovando assim a efetividade da técnica.

\section{REFERÊNCIAS}

1. Kusgoz A, Yldirrin T, Er k, Arslan I. Retreatment of a resected thoot associated whit a large perriapical lesion by using a triple antibiotic past and MTA: a case reported. JOE 2009; 35(11)1603-06.

2. Souza TS, Deonízio MA, Batista A, Kowalczuck A, Sydney GB. Regeneração endodôntica: existe um protocolo? Rev Odontol Bras Central. 2013; 22(63):12833.

3. Lovelace TW, Henry MA, Hargreaves KM, Diogenes A. Evaluation of the delivery of mesenchymal stem cells into the root canal space of necrotic immature teeth after clinical regenerative endodontic procedure. J Endod. 2011; 37(2):133-138.

4. Machado MEL, Haddad Filho MG, Aguiar CM. Endodontia - tópicos da atualidade. Nova Odessa: Napoleão Editora; 2015, p.346-73.

5. Lopes HP, Siqueira Jr JF. Endodontia - Biologia e Técnica. 4.ed. Rio de Janeiro: Elsevier - Campus; 2015, p. $760-773$.

6. Jung IY, Lee SJ, Hargreaves KM. Biologically base treatment of immature teeth with pupal necrosis: a case series. J Endod. 2008; 34(7):876-87.

7. Hargreaves KM, Geisler T, Henry M, Wang $\mathrm{Y}$. Regeneration potencial of the young permanent tooth: what does the future hold? J Endod. 2008; 34(37):51-56.

8. Alcade MP, Guimarães BM, Fernandes SL, Silva PAA, Bramante CM, Vivan RR, et al. Revascularização pulpar: considerações técnicas e implicações clínicas. Salusvita. 2014; 33(3):415-432.

9. Trevino EG, Patwardhand AN, Henry MA. Effects of irrigants on the survival of human stem cells of the apical papilla in a platelet-rich plasma scaffold in human root tips. J Endod. 2011; 37(8):1109-15.

10. Nagata JY, Gomes BP, Rocha Lima TF, Murakami LS, de Faria DE, Campos GR et al. Traumatized immature teeth treated with 2 protocols of pulp resvacularization. J Endod. 2014; 40(5):606-12.

11. Nosrat A, Seifi A, Asgary S. Regenerative endodontic treatment (revascularization) for necrotic immature permanent molars: a review and report of two cases with a new biomaterial. J Endod. 2011; 37(4): 562-7.

12. Shin SY, Albert JS, Mortman RE. One step pulp revascularization treatment of a immature permanent tooth with chronic apical abcess: a case report. Int Endod J. 2009;42(12):1118-26. 
13. Reynolds K, Johnson JD, Cohenca N. Pulp revascularization of necrotic bilateral bicuspids using a modified novel technique to eliminate potential coronal discoloration: a case report. Int Endod J. 2009; 42(1):84-92.

14. Galler KM, D'Souza RN, Federlin M, Cavender AC, Hartgerink JD, Hecker S. Dentin conditioning codetermines cell fate in regenerative endodontics. J Endod. 2011; 37(11):1536-41.

15. Graham L, Cooper PR, Cassidy N, Nor JE, Sloan AJ, Smith AJ. The effect of calcium hydroxide on solubilization of bio-active dentine matrix components. Biomaterials. 2006; 27(14):2865-73.

16. Turkistani J, Hanna A. Recent trends in the management of dento alveolar traumatic injuries to primary and young permanent teeth. Dent Traumatol. 2011; 27(1):46-54

17. Iwaya SI, Ikawa M, Kubota M. Revascularization of an immature permanent tooth with periradicular abscess after luxation. Dent Traumatol. 2011; 27(1):55-8

18. Bose R, Nummikoski P, Hargreaves K. A retrospective evaluation of radiographic outcomes in immature teeth with necrotic root canal systems treated with regenerative endodontic procedures. J Endod. 2009; 35(10):1343-9.

19. Dhillon H, Kaushik M, Sharma R. Regenerative endodontics-Creatinh new horizons. J Biomed Mater Res B Appl Biomater. 2016 :104(4):676-85.

20. Bansal R, Bansal R. Regenerative endodontics: a state of the art. Indian J Dent Res. 2011; 22(1):122-31.

21. Souza Filho FJ. Tratamento de dentes com rizogênese incompleta: revitalização ou apicificação. In: Endodontia passo a passo: evidências clínicas. São Paulo: Artes Médicas; 2015, p.166-175.

22. Ding RY, Cheung GS, Chen J, Yin XZ, Wang Q, Zhang C. Pulp revascularization of immature teeth with apical periodontitis: a clinical study. J Endod. 2009; 35(5):745-9.

23. Sarris S, Tahmassebi JF, Duggal MS, Cross IA. A clinical evaluation of mineral trioxide aggregate for root-end closure of non-vital immature permanent incisors in children-a pilot study. Dent Traumatol. 2008; 24(1):79-85

24. Pradhan DP, Chawla HS, Gauba K, Goyal A Comparative evaluation of endodontic management of teeth with unformed apices with mineral trioxide aggregate and calcium hydroxide. J Dent Child (Chic). 2006; 73(2):79-85.

25. Porter ML, Bertó A, Primus CM, Watanabe I. Physical and chemical properties of new-generation endodontic materials. J Endod. 2010; 36(3):524-8.

26. Chen MY, Chen KL, Chen CA, Tayebaty F, Rosenberg PA, Lin LM. Responses of immature permanent teeth with infected necrotic pulp tissue and apical periodontitis/abscess to revascularization procedures. Int Endod J. 2012;45(3):294-305.

27. Chueh LH, Ho YC, Kuo TC, Lai WH, Chen YH, Chiang CP. Regenerative endodontic treatment for necrotic immature permanent teeth. J Endod. 2009;35(2):160-4.

\section{CONFLITO DE INTERESSES}

Os autores declaram não haver conflitos de interesse.

\section{AUTOR PARA CORRESPONDÊNCIA}

\section{Lucieni Cristina Trovati Moreti}

lucienimoreti@hotmail.com

Submetido em 21/04/2017

Aceito em 06/06/2017 